\title{
EVALUATION OF HUMAN POSTURE AND ERGONOMICS BY APPROPRIATE ASSESSMENT TOOL IN A MEDIUM SCALE MANUFACTURING INDUSTRY
}

\author{
S. NALLUSAMY ${ }^{1 *}$, PANKAJ SHAH ${ }^{2}$, SURAJ KUMAR SINGH ${ }^{3}$, NATIONAL PILLA ${ }^{4}$ \\ \& M. D. HAMID REZA ${ }^{5}$ \\ ${ }^{I}$ Professor and Dean, Dr. M.G.R. Educational and Research Institute, Chennai, Tamil Nadu, India \\ ${ }^{2,3,4,5}$ UG Scholar, Department of Mechanical Engineering, Dr. M.G.R. Educational and Research Institute,
}

Chennai, Tamil Nadu, India

\begin{abstract}
In current health scenario, Musculoskeletal Disorders (MSD) is frequent grumbles surrounded by the employees occupied at stationary work that needs cyclic motion of the upper limbs in spite of their specific business. System and machine operators are seated and continuously work for a long time by about 8hourswithout moving. The employees are mostly using their arm with hand muscles and also they are lean to be a poor posture of body. The consequential MSD develop weakness, pain and discomfort. The objective of this research is an ergonomic assessment of both white collars and machine operators in a medium scale manufacturing industry to categorize the important serious positions in design of aged equipments and position of operational practices. An assessment is going to carried out for design, motor and pump assembly along with managerial section by means of a random sampling technique. The anthropometric of the workers and working table dimensions were obtained with comparison. The RULA, ROSA, REBA ergonomic assessment methods are used to assess the risk factors occurred by the implementation of wretched position in their place of work. NIOSH method is used to evaluate to Lifting Index (LI), 3DSSPP is used to evaluate the simulation study for postural and fatigue analysis. The observed results reveal a prevalence of symptoms of musculoskeletal disorders. There should be an important relationship stuck between MSD and abnormal height of worktable which leads to adopt wrong posture habits. The organization must change the old style furniture's and correct the uneven worktable height according to the employee's anthropometry. And also to offer best training to keep up their high-quality live out position at their workplace.
\end{abstract}

KEYWORDS: Musculoskeletal Disorders, Fatigue Analysis, Ergonomic Assessment Tools, Anthropometry Measurement \& Work Posture

Received: Apr 13, 2020; Accepted: May 04, 2020; Published: Jun 01, 2020; Paper Id.: IJMPERDJUN202076

\section{INTRODUCTION}

Manufacturing industries have learnt that happy workers, better safety are critical at workplace that improves the operation for getting the optimum production. Productivity of the worker greatly depends upon the ergonomic design of workstations. Ergonomics is the science of work focusing on the ability to work as per the demand of the job [1]. It helps in fitting the activities and to improve the performance of the people by enhancing comfort with health and safety. Implementation of ergonomic solutions can make employees work with more comfort and with more power. Efficient ergonomics in workstation design improves the interaction between man and machine systems. Various studies regarding operator performance and comfort in repetitive task have been done. As human performance largely depends on the places they work and the way they work anthropometry play is an important part in the designing of the working speed. If anthropometry data mismatches with workstation design, workstation 
functions with less efficiency. Proper methodology has to be proposed for analysis and classifications of workstation layout configuration in relation to both technological and environmental parameters. When work is performed in awkward postures or with excessive effort, fatigue and discomfort may result that would result in damaging the muscles, tendons, ligaments, nerves, and blood vessels. Injuries of this type are known as MSD [2, 3]. This study has been aimed at assessing the ideal ergonomic approaches that could be recommended to machine operators in the assembly lines of a manufacturing company and the major goal is to identify the powerful principles in common furniture designs and uneven working table height as they interact with working posture habits. Aspecific interest shown in this study due tothe administration board could not be reached to the workers completely for their working environment,and MSD problem is also present due to uncomfortable working postures[4]. Over the years we could see that, there has been a tremendous development of measuring tools. Proper tools and correct measurement techniques are required to create Physical Demand Descriptions (PDD). For our purpose, the measuring instruments and the proper way to measure various aspects of tasks are video camera, small bone and long bone caliper, gonio meter steel rule and measuring tape.The objective of this research is to assessthe current working position of managerial section and machine operators in the assembly lines of a manufacturing companyto solve the MSD problem of the workers, completely.

Measuring Instruments and Measurement Factors: Using proper tools as well as correct measurementtechniques are necessary to create Physical DemandDescriptions (PDDs) that will be both accurate and useful.The equipment and the proper way to measure various aspects of tasks are video camera, small bone caliper, long bone caliper, goniometer, steel rule and measuring tape.

\section{LITERATURE REVIEW}

Nowadays, it is practically impossible to find an office or a shop floor without a computer workplace. As necessity has become unavoidable, a system operator working for a prolonged time often suffered from musculoskeletal disorder problems. Such occupational health and safety problems are continuously increasing, which leads to reduce the performance and dissatisfaction of the workers. Three manual assembly operations in a car production line were selected as case studies and investigated. In the first case study, the upper arm elevation angle was found to be greater leading to an unacceptable posture of the upper limb. In the second case study, it was observed that, both the bending of the trunk and the upper arm elevation was needed for all the three anthropometric percentiles and the third case study showed the trunk bending to be greater and hence P50 was preferred [5, 6]. Study on design on reducing musculoskeletal risk factors was conducted at an automotive component manufacturing unit. The measurement showed the current workbench height to be $87 \mathrm{cms}$ from the floor, which was too low. The worker was found to have not reached the maximum recommended distance of 50cms from the worker's body to the work piece [7]. Similarly, a prospective study was focused on reducing shoulder loadings by redesigning nine workstations. The shoulder angle is greater than 400 , which lead to elbow pain in the current workstation and in the redesigned work station the shoulder angle is fixed as 250 to avoid shoulder and elbow pain [8]. Ergonomically redesigned workstation served as an effective intervention program in reducing female fabrication worker's awkward shoulder postures and other shoulder discomfort symptoms. The intervention program was effective, when the workstation was redesigned with appropriate height measurement of the keyboard shelf that would reduce the worker's shoulder flexion and abduction angles. By lowering the keyboard shelf's height from 1100 to $950 \mathrm{~mm}$, shoulder flexion and abduction angles came to less than 15 degree in both sitting and standing positions [9, 10].A study was done to identify the factors causing discomfort/pain experienced by the workerswith detailed questionnaire and checklist. Discomfort level was 
minimized for more than $50 \%$ of the welders with improved RULA control graph [11, 12$]$.

A case study was performed to verify the adequacy of furniture to the students and found that, $98.2 \%$ of the analyzed positions of students are between medium to very high risk and $46.7 \%$ have complaints of pain in the hips and thighs. Hence, the height of the table for the studentswere matched with the elbow height and the arms was able to reach the top of the table in the standing posture [13]. A study was conducted on 15 workers in a small scale manufacturing industry. The RULA and REBA method determined $40 \%$ and 53\%of the workers to be at high risk respectively. As the workers were bending their trunk to a higher degree which was not acceptable, they needed a necessary change. So the workers were suggested to keep their trunk straight while working $[14,15]$. A research article presented literature on the NIOSH lifting equation and through ergonomic redesign, it was suggested that the load could be brought closer to the worker by means of training. Height of the object being placed could be raised while the origin and destination of lift brought closer to reduce the angle of twist and the result was a safer LI < 1.0 [16, 17]. An ergonomic intervention assessment tool was used to calculate the Recommended Weight Limit (RWL) for lifting tasks and to identify the hazardous lifting tasks. To analyze Manual Material Handling (MMH) and working posture of the operators, Three Dimensional Static Strength Prediction Program (3DSSPP) software was used. Accordingly, operators' working posture was observed to be at an unacceptable position. Then, with an improvement made on the design of MMH device of cart's roller, the result showed that the forces required by the operators to push and pull the sliver cans got reduced from $931.77 \mathrm{~N}$ to $194.23 \mathrm{~N}$ [18]. Based on the above literature reviews, a study was carried out to investigate the work posture of employees to improve their comfort, and to develop ergonomically designed workstation that shall reduce postural stress and thereby results in productivity improvement in a pump manufacturing industry.

\section{PROBLEM DEFINITION AND OBJECTIVES}

Based on the literature, the following problems were identified for this research.

- MSD problem is identified due to uncomfortable working postures

- Extended work on the system users and assembly line workers in a manufacturing firm areexperiencing more pain during their work.

- Workers awkward postures affectthe different parts of thebody both sitting in computer andstanding near machineover period of time. People with lack of ergonomic knowledge have poor accessibility to dooperation.

- White-collar workers in design section and machine operates in assembly line are standing in oddwork surface height.

The main objectives of this research are as follows.

- To analyze an office workplace and assembly lineergonomically for employees using Anthropometricdata.

- To investigate the existing office furniture workplacedimensions and assembly lines dimensions.

- To collect Anthropometric data for white collar joband assembly lines employees agedbetween 20 to 40 years

- To suggest a dimensions for office workplace andassembly line using Measured Anthropometric Data

- $\quad$ To appraise the workstation using RUL, ROSAand REBA Ergonomic tools 
- $\quad$ To evaluate the lifting index using NIOSH

- $\quad$ To analyze the system using Ergonomic AnalysisSoftware (3DSSPP) and validate.

\section{METHODOLOGY}

The intention of the research is to expose ways toreduce fatigue level of the workers and analyze thepostural and MSD using variousergonomics assessment tools.Here, initially a data has to be collected andunderstood regarding their nature of work, work environment and their present postures.Then the data collection is done by visual methodat thepresent work station and questionnaires from the employees followed by brainstorming session. The methodology of the project is shown in above figure 1.With welldefined methodology, high prioritized fatigue problem is fixed for evaluation for same working conditions and postural analysis is done. The next chapter focuses on data collection of present level and various techniques used for analysis.

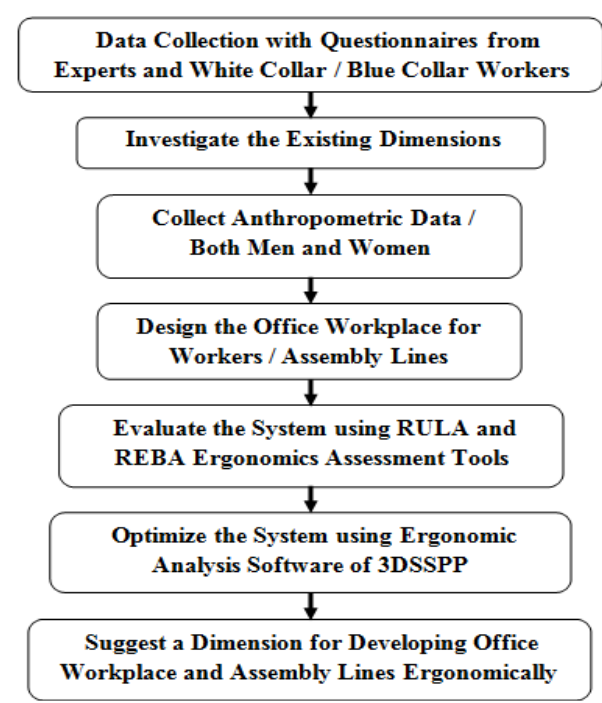

Figure 1: Methodology Flow Chart.

\section{DATA COLLECTION AND ANALYSIS}

Questionnaires related to various issues faced by the employees in their work place,and time of work was prepared and feedback was receivedfrom them. Staff appraisal was carried out byQuick Exposure Checklist (QEC).Sample Questionaries format is shownin table 1. The survey was done with some common measures such as sitting height, wrist angle, neck angle, elbow support, trunk position, spinal cord position and interfaces of computer users. 
Table 1:Questionnaires for Machine Operators

Section B: Lifting and Carrying - More Detailed assessment, where necessary

\begin{tabular}{|c|c|c|c|c|c|c|}
\hline \multirow{2}{*}{ Questions to consider } & \multicolumn{4}{|c|}{ If 'Yes', tick appropriate level of risk } & \multirow{2}{*}{$\begin{array}{c}\text { Problems occuring from the task. (Male } \\
\text { rough notesin this column in preparation for } \\
\text { the possible remedial action to be taken.) }\end{array}$} & \multirow{2}{*}{$\begin{array}{l}\text { Possible remedial action, eg changes that } \\
\text { need to be made to the task, load, working } \\
\text { environment etc. Who needsto be involved in } \\
\text { implementing the changes? }\end{array}$} \\
\hline & Low & Med & High & $\mathrm{N} / \mathrm{A}$ & & \\
\hline \multicolumn{7}{|l|}{ Do the tasks involve: } \\
\hline \multicolumn{7}{|l|}{ Holding loads away from torso? } \\
\hline \multicolumn{7}{|l|}{ Twisting? } \\
\hline \multicolumn{7}{|l|}{ Stopping? } \\
\hline \multicolumn{7}{|l|}{ Reaching upwards? } \\
\hline \multicolumn{7}{|l|}{ Large vertical movement? } \\
\hline \multicolumn{7}{|l|}{ Long carrying distances? } \\
\hline \multicolumn{7}{|l|}{ Strenuous pushingor pulling? } \\
\hline \multicolumn{7}{|l|}{ Unpredictable movement of loads? } \\
\hline \multicolumn{7}{|l|}{ Repetitive handling? } \\
\hline \multicolumn{7}{|l|}{ Insufficient rest or recovery? } \\
\hline \multicolumn{7}{|l|}{ A work rate umposed by recovery? } \\
\hline \multicolumn{7}{|l|}{ Are theloads: } \\
\hline \multicolumn{7}{|l|}{ Heavy? } \\
\hline \multicolumn{7}{|l|}{ Bulky or Unwidly? } \\
\hline \multicolumn{7}{|l|}{ Difficult to Grasp? } \\
\hline \multicolumn{7}{|l|}{ Unstable or Unpredictable? } \\
\hline Intrinsically harmful (eg sharphot) & & & & & & \\
\hline
\end{tabular}

Questionnaires such as ergonomic assessment checklist, QEC, health and safety executive checklist and USGBC checklists are chosen to conduct assessment at both system users and machine operators. Table 2 shows the results of QEC for motor assembly assessment.

Table 2: Results of QEC for Motor AssemblyAssessment

\begin{tabular}{|l|c|c|c|c|}
\hline \multicolumn{1}{|c|}{ Score } & Low (\%) & Moderate (\%) & High (\%) & Very High (\%) \\
\hline Back & & & 10 & 90 \\
\hline Shoulder / Arm & & & & 100 \\
\hline Wrist /Hand & & & 30 & 70 \\
\hline Neck & & 20 & 10 & 70 \\
\hline Driving & 100 & & & \\
\hline Vibration & 20 & 80 & & \\
\hline WorkPace & & 80 & 20 & \\
\hline 20Stress & & 20 & 60 & 20 \\
\hline
\end{tabular}

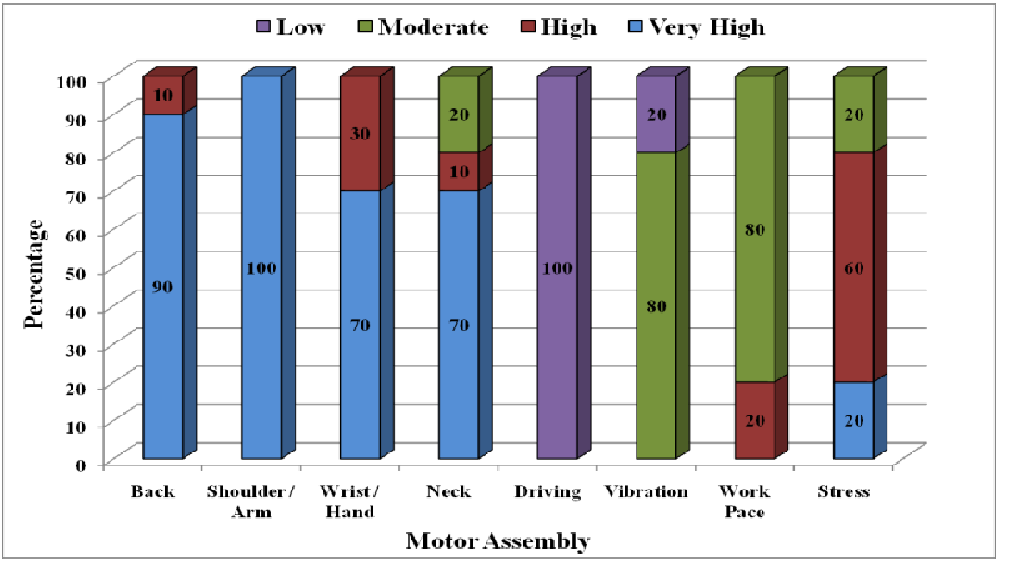

Figure 2: Graphical Representation of Ergonomic Assessment Checklist for Motor Assembly.

From figure 2 it was found that, about $70 \%$ people arehaving very high problems in neck and wrist and $100 \%$ of employees are having vey high pains in shoulder. 
Table 3: Results of USGB Checklist for System Users

\begin{tabular}{|c|c|c|c|c|c|c|c|c|c|c|c|c|c|c|c|}
\hline $\begin{array}{c}\text { Ergonomic } \\
\text { Issues }\end{array}$ & $\begin{array}{c}\text { Comfortable } \\
\text { Supported } \\
\text { Neutral } \\
\text { Position }\end{array}$ & $\begin{array}{l}\text { Work } \\
\text { Items } \\
\text { within } \\
\text { Reach }\end{array}$ & $\begin{array}{c}\text { Chair } \\
\text { Good } \\
\text { Back } \\
\text { Support }\end{array}$ & $\begin{array}{l}\text { Keyboard } \\
\text { with } \\
\text { Straight } \\
\text { Hands }\end{array}$ & $\begin{array}{c}\text { Mouse } \\
\text { with } \\
\text { Straight } \\
\text { Hands }\end{array}$ & $\begin{array}{c}\text { Screen } \\
\text { Comfort } \\
\text { wothout } \\
\text { Neck Twist }\end{array}$ & $\left|\begin{array}{c}\text { Document } \\
\text { within } \\
\text { Range and } \\
\text { Positioned }\end{array}\right|$ & $\begin{array}{c}\text { Not } \\
\text { Glare }\end{array}$ & $\begin{array}{c}\text { Sufficient } \\
\text { Light to } \\
\text { Work }\end{array}$ & $\begin{array}{c}\text { Comfortble } \\
\text { Working } \\
\text { Height }\end{array}$ & $\begin{array}{c}\text { Adequate } \\
\text { Leg } \\
\text { Clearance }\end{array}$ & $\begin{array}{c}\text { Feet } \\
\text { Support } \\
\text { on Floor }\end{array}$ & $\begin{array}{c}\text { Never } \\
\text { Experienced } \\
\text { Discomfort }\end{array}$ & $\begin{array}{c}\text { Comfortable } \\
\text { Temperature }\end{array}$ & $\begin{array}{c}\text { Acceptable } \\
\text { Background } \\
\text { Noises }\end{array}$ \\
\hline Percentage & 57 & 79 & 57 & 86 & 79 & 86 & 100 & 21 & 86 & 79 & 79 & 86 & 14 & 21 & 21 \\
\hline
\end{tabular}

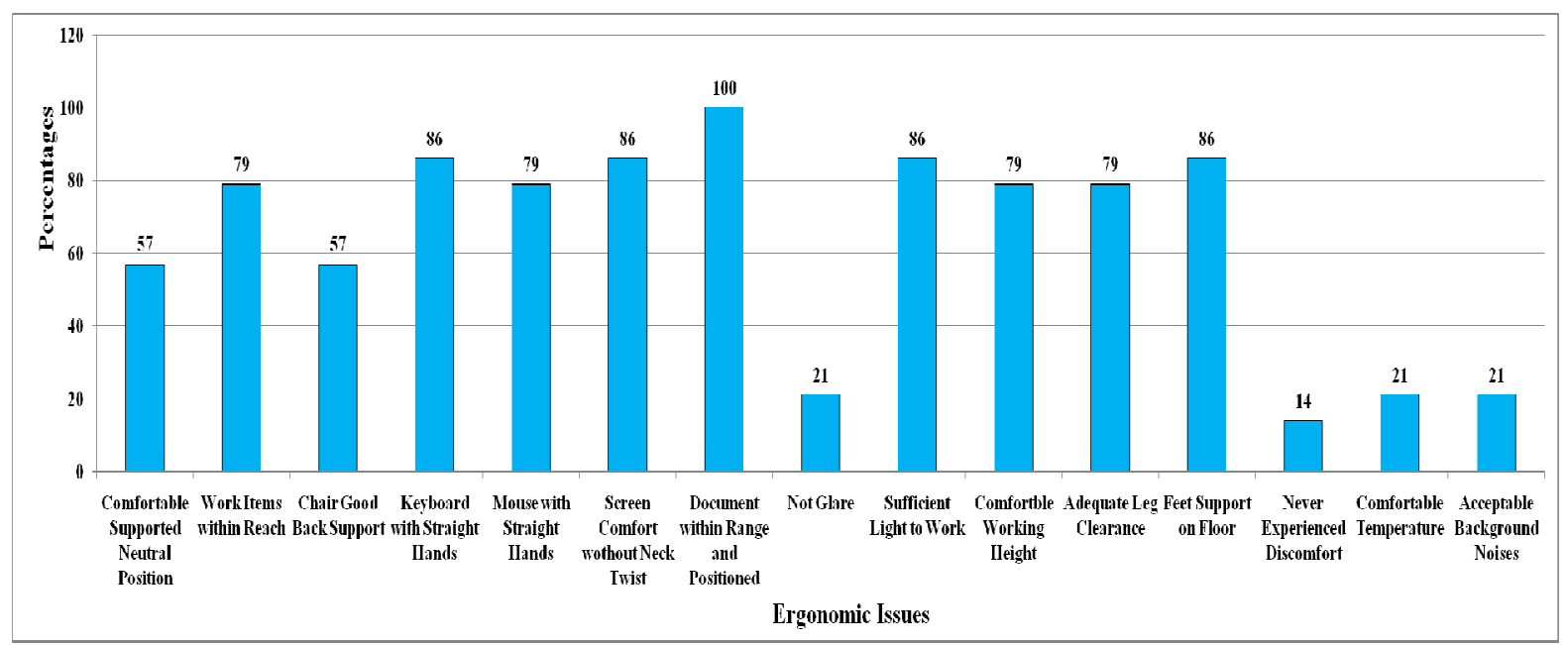

Figure 3: Graphical Representation of USGB Checklist for System Users.

Table 3 shows the results of USGB checklist for system users, where $21 \%$ people have problems in Glare, only $14 \%$ of people feels never experienced discomfort in working environment and so on are shown in figure 3.

\section{ERGONOMIC ASSESSMENT}

\section{RULA}

By means of RULA worksheet, RULA score is evaluated for both assembly lines andresults are tabulated in Table 4.RULA score 7 is very high risk and needs suitable alternative implementation as earlier.RULA score calculation is done in figure 4 based on neck, trunk, upper arm, and lower arm angles.

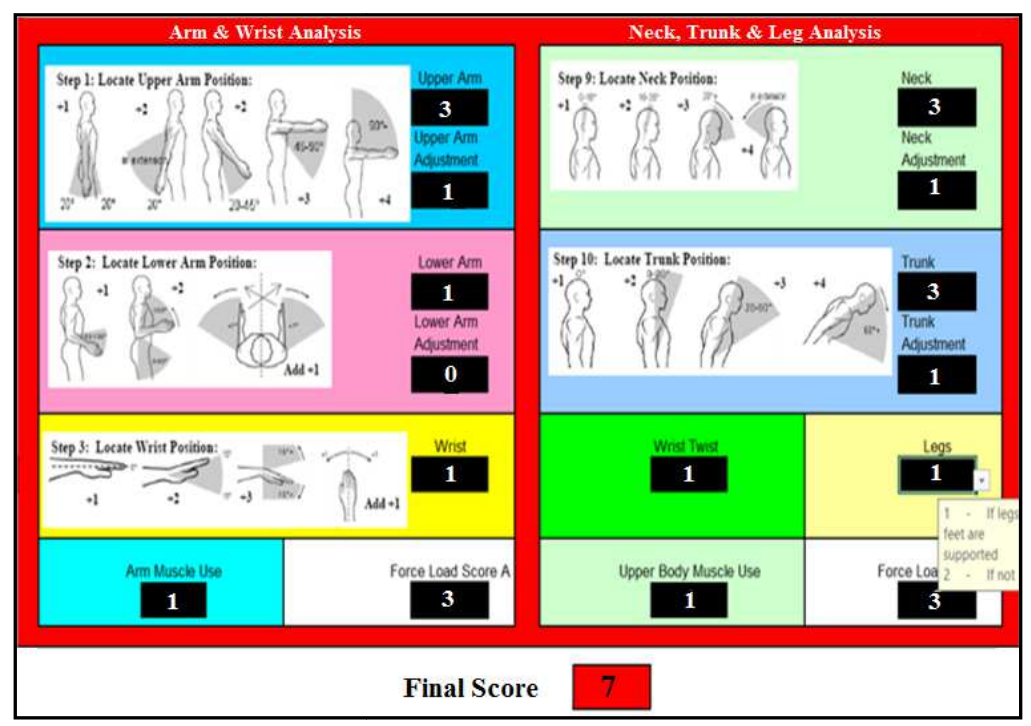

Figure 4: RULA Results of Motor Assembly Lifting. 
Table 4: RULA Score

\begin{tabular}{|l|c|c|}
\hline \multicolumn{1}{|c|}{ Case } & RULA Score & Action \\
\hline Motor Assembly & 7 & Very High Risk, Now executemodification \\
\hline Pump Assembly & 7 & Very High Risk, Now execute modification \\
\hline
\end{tabular}

\section{ROSA}

ROSA is checklist, designed by picture based position to computethe risk factors in an office workingatmosphere.ROSA is developed with picture basedobservations and chart analysis method such as RULA andREBA.ROSA score calculation is done and risk is identified using table 5.

Table 5: ROSA Table Score

\begin{tabular}{|c|c|c|c|c|c|c|c|c|c|c|c|}
\hline & & \multicolumn{10}{|c|}{ Peripherals and Monitor } \\
\hline & & 1 & 2 & 3 & 4 & 5 & 6 & 7 & 8 & 9 & 10 \\
\hline \multirow{10}{*}{ 昙 } & 1 & 1 & 2 & 3 & 4 & & 6 & 7 & 8 & 9 & 10 \\
\hline & 2 & 2 & 2 & 3 & 4 & & 6 & 7 & 8 & 9 & 10 \\
\hline & 3 & 3 & 3 & 3 & 4 & & 6 & 7 & 8 & 9 & 10 \\
\hline & 4 & 4 & 4 & 4 & 4 & & 6 & 7 & 8 & 9 & 10 \\
\hline & 5 & 5 & 5 & 5 & 5 & & 6 & 7 & 8 & 9 & 10 \\
\hline & 6 & 6 & 6 & 6 & 6 & & 6 & 7 & 8 & 9 & 10 \\
\hline & 7 & 7 & 7 & 7 & 7 & 7 & 7 & 7 & 8 & 9 & 10 \\
\hline & 8 & 8 & 8 & 8 & 8 & 8 & 8 & 8 & 8 & 9 & 10 \\
\hline & 9 & 9 & 9 & 9 & 9 & 9 & 9 & 9 & 9 & 9 & 10 \\
\hline & 10 & 10 & 10 & 10 & 10 & 10 & 10 & 10 & 10 & 10 & 10 \\
\hline
\end{tabular}

\section{ANTHROPOMETRY}

Anthropometry values of employees are collected for bothmotor assembly and system operatorsand theirpercentile and mean values are determined.The results of motor assembly and system operators are shown in table 6 and table 7 , respectively. Based on the anthropometric measurements taken in motor assembly percentile values, like P5, P50 andP95 are calculated. Then Hypothesis test correlation is determined. Based on the correlation results P> 0.05 , P50 values are acceptable and taken for design considerations, which is shown in table 7. P50 values are acceptable. Minimum, maximum and range values are also determined and shown in table 6 and table 7.

Table 6: Anthropometry and Percentile Population of Motor Manufacturing

\begin{tabular}{|c|c|c|c|c|c|c|c|c|}
\hline Department & Mean & SD & P5 & P50 & P95 & Max & Min & Range \\
\hline NH & 2.95 & 0.58 & 1.99 & 2.95 & 3.91 & 4.00 & 2.25 & 1.75 \\
\hline SW & 17.45 & 1.31 & 15.28 & 17.45 & 19.62 & 20.75 & 16.00 & 4.75 \\
\hline SH & 19.85 & 1.06 & 18.10 & 19.85 & 21.60 & 22.00 & 18.00 & 4.00 \\
\hline UA & 11.95 & 1.34 & 9.74 & 11.95 & 14.16 & 13.75 & 9.13 & 4.62 \\
\hline LA & 11.51 & 0.96 & 9.93 & 11.51 & 13.10 & 13.00 & 9.75 & 3.25 \\
\hline W & 7.90 & 0.80 & 6.58 & 7.90 & 9.22 & 9.13 & 6.50 & 2.63 \\
\hline UL & 19.11 & 1.24 & 17.08 & 19.11 & 21.15 & 21.00 & 16.75 & 4.25 \\
\hline LL & 16.01 & 2.04 & 12.65 & 16.01 & 19.38 & 18.50 & 11.25 & 7.25 \\
\hline F & 8.60 & 1.02 & 6.92 & 8.60 & 10.28 & 10.00 & 7.00 & 3.00 \\
\hline Tragion & 1.20 & 0.19 & 0.89 & 1.20 & 1.51 & 1.50 & 1.00 & 0.50 \\
\hline HR & 4.08 & 0.10 & 3.92 & 4.08 & 4.24 & 4.30 & 4.00 & 0.30 \\
\hline
\end{tabular}


Table 7: Anthropometry and Percentile Population of System User

\begin{tabular}{|c|c|c|c|c|c|c|c|c|}
\hline Department & Mean & SD & P5 & P50 & P95 & Max & Min & Range \\
\hline NH & 3.13 & 0.51 & 2.29 & 3.13 & 3.98 & 4.00 & 2.25 & 1.75 \\
\hline SW & 17.89 & 1.33 & 15.71 & 17.89 & 20.08 & 20.50 & 16.00 & 4.50 \\
\hline SH & 18.95 & 1.62 & 16.27 & 18.95 & 21.63 & 22.00 & 16.50 & 5.50 \\
\hline UA & 11.27 & 1.16 & 9.36 & 11.27 & 13.18 & 13.25 & 9.00 & 4.25 \\
\hline LA & 11.88 & 0.81 & 10.54 & 11.88 & 13.21 & 13.00 & 10.50 & 2.50 \\
\hline W & 8.26 & 0.79 & 6.95 & 8.26 & 9.57 & 9.50 & 7.25 & 2.25 \\
\hline UL & 18.93 & 1.29 & 16.80 & 18.93 & 21.60 & 21.00 & 16.75 & 4.25 \\
\hline LL & 16.49 & 1.18 & 14.55 & 16.49 & 18.43 & 18.50 & 14.75 & 3.75 \\
\hline F & 8.64 & 0.81 & 7.30 & 8.64 & 9.98 & 10.00 & 7.00 & 3.00 \\
\hline Tragion & 1.20 & 0.17 & 0.92 & 1.20 & 1.47 & 1.50 & 1.00 & 0.50 \\
\hline HR & 4.10 & 0.10 & 3.94 & 4.10 & 4.27 & 4.30 & 4.00 & 0.30 \\
\hline
\end{tabular}

\section{HISTOGRAM AND HYPOTHESIS}

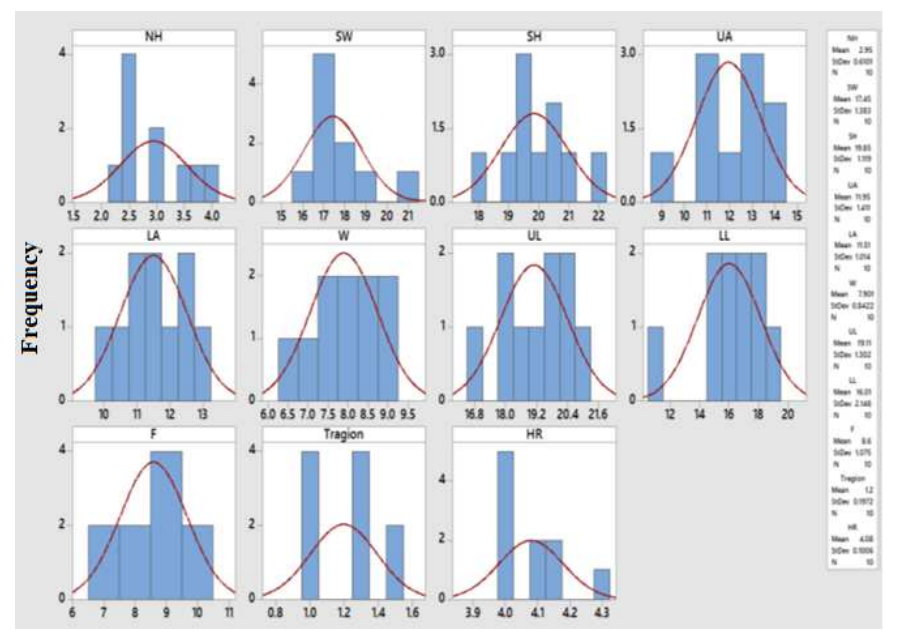

Figure 5: Histogram Chart at Motor Assembly.

When $\mathrm{P}>0.05$, Null hypothesis is not rejected

And $\mathrm{P}<0.05$ Null hypothesis is rejected

Mean values, standard deviations for all factors aredetermined and Histogram is drawn and is shown in figure 5 and figure 6.

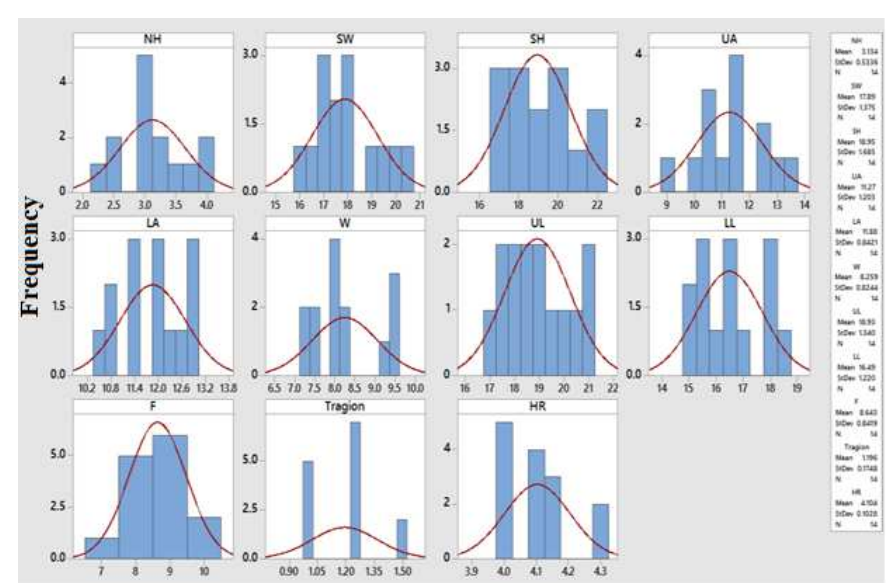

Figure 6: Histogram Chart at System Users. 


\section{SIMULATION RESULTS}

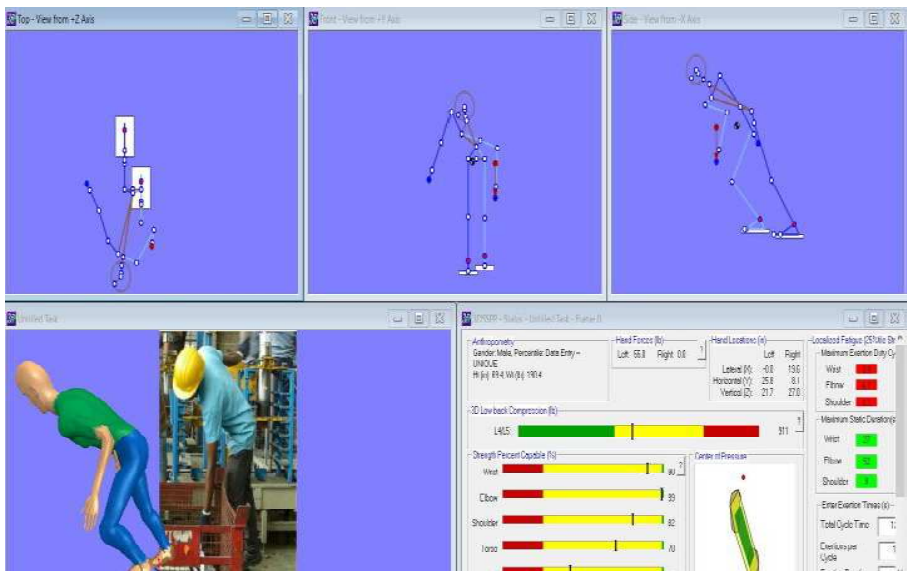

Figure 7: Simulation of Motor Assembly.

Ergonomic analysis is done on 3DSSPP Simulation software for motor assembly and system users and various postural analysesare done. 3DSSPP simulation is drawn and stress level is calculated for assembly lines, as shown in figure 7. Analysis summary report and localized fatigue reports are generated, centre of pressure point is out of range and it is unacceptable, as shown in figure 8 and figure 9. Simulation results are unacceptable and proposed one is simulated based on 50th percentile of the population.

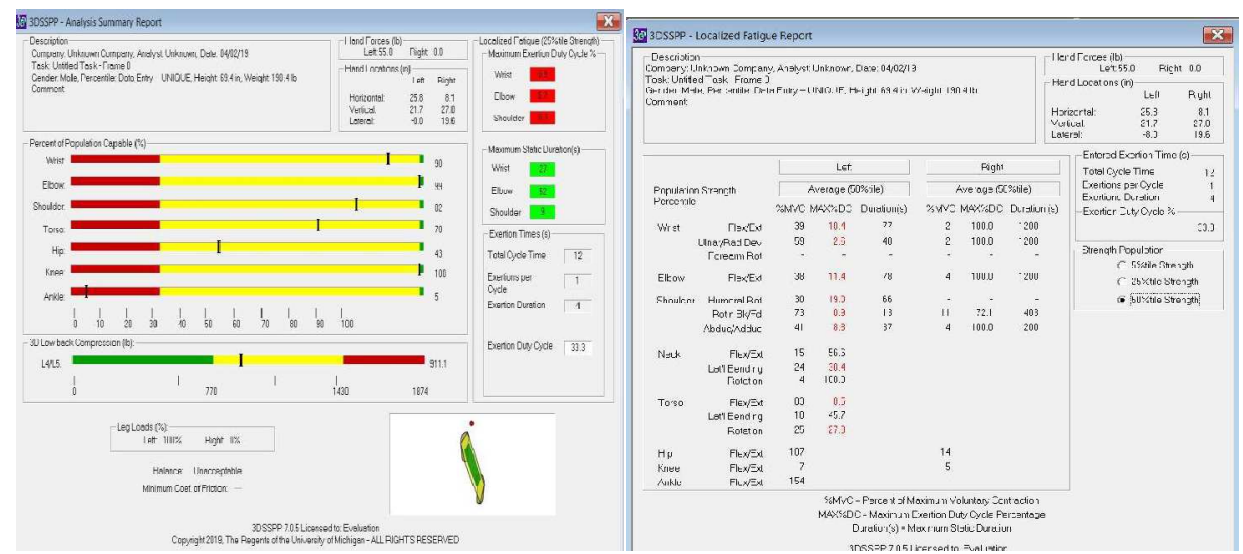

Figure 8: Analysis Summary Report of Motor AssemblyFigure 9: Localized Summary Report of Motor Assembly.

\section{PROPOSED WORK FOR MOTOR ASSEMBLY LINE}

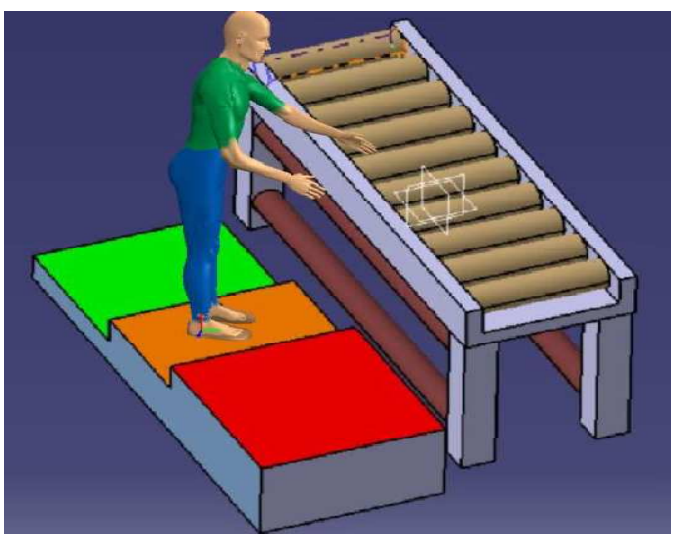

Figure 10: Proposed Layout for Motor Assembly. 
In this proposed layout, person is working as per the P50 anthropometricmeasurement of workers, In order to mitigate fatigue level ofthe workers, as shown in figure 10, the proposed height is shown in table 8 . It is the comfortable level of work, which reduces overall fatigue and percentage of Maximum Voluntary Contraction (\%MVC).

Table 8: Proposed Height for Motor Assembly

\begin{tabular}{|c|c|}
\hline Proposed Height & P50 Height \\
\hline 60 inches & 44 inches \\
\hline
\end{tabular}

Existing Sitting Posture for System User

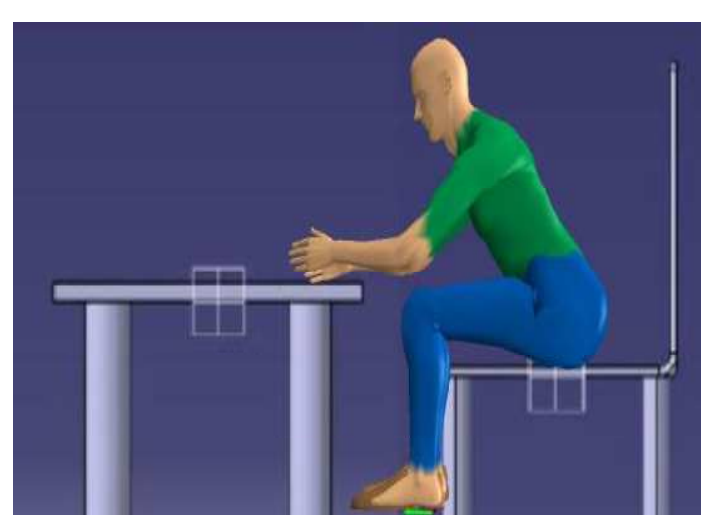

Figure 11: Existing Posture Design for System Users.

In this existing system, seat height is shown and it is uncomfortable tosit and work for prolonged time, as shown in figure 11, and their measurements are given in table 9. Proposed seat and table height should be in range of $45-50 \mathrm{cms}$ and $70-80 \mathrm{cms}$ in height, respectively. Ergonomic standard dimension as per OSHA standard to be proposed is shown in table 10 .

Table 9: Measured Dimensions of Existing System Users

\begin{tabular}{|l|l|l|}
\hline 191 & $41-42$ & $67-70$ \\
\hline 180 & $38-40$ & $62-66$ \\
\hline 170 & $35-37$ & $59-61$ \\
\hline
\end{tabular}

Table 10: Ergonomic Standard Dimensions based on AnthropometricHeight for Proposed System Users

\begin{tabular}{|c|c|c|}
\hline 191 & $49-54$ & $83-85$ \\
\hline 180 & $47-50$ & $79-82$ \\
\hline 170 & $44-48$ & $75-78$ \\
\hline
\end{tabular}

\section{CONCLUSIONS}

The objective of ergonomic analysis was carried out on system user and machine operator work posture. From the results of numerical and simulation analysis, following decisions were arrived.

- height should be in between $45-50 \mathrm{cms}$ and hence the user need not necessary to bend while using system and finally L4 In this proposed layout, person is working as per the P50 anthropometric measurement of workers; it is the comfortable level of work which reduces overall fatigue and \% MVC.

- $\quad$ Proposed seat and table height should be in range of $45-50 \mathrm{cms}$ and $70-80 \mathrm{cms}$ in height respectively.

- The percentage of maximum exertion duty cycle and maximum static duration gets increased in suggested model 
as compared to previous model in both the cases.

- To avoid high fatigue and awkward posture, suggestions were provided based on anthropometry and hence, bending is avoided and reachability is improved.

- In system user, seat /L5 back compression was reduced in both the cases.

\section{REFERENCES}

1. Schaub, K., Caragnano, G., Britzke, B. \& Bruder, R. (2013). The European assembly worksheet, Theoretical Issues in Ergonomics Science, 14(6), 616-639.

2. Ivaniria Tecilla Guimaraes Souza, Celia Roberta Buss Buski, Eduardo Concepcion Batiz \& Ana Lucia Berretta Hurtado. (2015). Ergonomic analysis of a clothing design station. Applied Human Factors and Ergonomics Procedia Manufacturing, 3, $4362-4369$

3. Gunji Venkata Punna Rao, Nallusamy, S. and Rajaram Narayanan, M. (2017). Augmentation of production level using different lean approaches in medium scale manufacturing industries. International Journal of Mechanical Engineering and Technology, 8(12), 360-372

4. Nilufer Ozturk \& Melek Nihal Esin. (2015). Investigation of musculoskeletal symptoms and ergonomic risk factors among female sewing machine operators in Turkey. International Journal of Industrial Ergonomics, 41, 585-591

5. Raffaele Castellone, Stefania Spada, Giovanni Caiazzo\& Maria Pia Cavatorta. (2017). Assessment of anthropometric differences in the design of workstations: Case studies of an automotive assembly line. International Journal of Applied Engineering Research, 12(14), 4549-4555.

6. Baba MdDeros, Nor Kamaliana Khamis, Ahmad Rasdan Ismail, HarisJamaluddin, Azmi Mat Adam \& Sarudin Rosli. (2011). An ergonomics study on assembly line workstation design. American Journal of Applied Sciences, 11, 1195-1201

7. Al-Marwani \& Al-Juhani, M. (2015) Neck and upper back pain among eye care professionals. Occupational Med (Lond), 65(9), 753-757

8. Mahendra, K.C., Virupaksha, H. and Thimmana Gouda, A. (2016). Ergonomic analysis of welding operator postures. International Journal of Mechanical and Production Engineering, 4, 01-09

9. Lennart Dimberg, Jasminka Goldoni Laestadius, Sandra Ross \& Ida Dimberg. (2015). The changing face of office ergonomics. The Ergonomics Open Journal, 8, 38-56

10. Md Yusop, M.S., Mat, S., Ramli, F.R., Dullah, A.R., Khalil, S.N.\& Case, K. (2018). Design of welding armrest based on ergonomics analysis: Case study at educational institution in Johor Bauru, Malaysia. Journal of Engineering and Applied Sciences, 13(1), 309-313

11. Hyer, J.N. (2015). National survey of back \& neck pain amongst consultant ophthalmologists in the United Kingdom. International Ophthalmology, 35(6), 769-775

12. Libin, T. Panicker, Deenathayalan, T.\& Rajmohan, P. (2017). Ergonomic evaluation of work posture by REBA in heavy industries. Advances in Natural and Applied Sciences, 11(7), 868-873

13. Kushwaha, D.K.\& Prasad Kane. (2016). Ergonomic assessment and workstation design of shipping crane cabin in steel industry. International Journal of Industrial Ergonomics, 52, 29-39

14. Worawan Poochada \& Sunisa Chaiklieng. (2015). Ergonomic risk assessment among call center workers. Procedia Manufacturing, 3, 4613- 4620 
15. Sandip B.Wanave \& Manish K. Bhadke. (2013). An ergonomic evaluation and assessment of the workstation to improve the productivity for an enterprise-A review. International Journal of Engineering Research and Applications, 3, 1598-1602

16. Nallusamy, S., Suganthini Rekha, R., Balakannan, K., Chakraborty, P.S. and Gautam Majumdar. (2015). A proposed agile based supply chain model for poultry based products in India. International Journal of Poultry Science, 14(1), 57-62

17. Rashmi Shahu. (2016). The NIOSH lifting equation for manual lifting and its applications. Journal of Ergonomics, 6(2), 01-10

18. Kaleand, P.N. and Vyavahare, R.T. (2016). Ergonomic analysis tools: A review. International Journal of Current Engineering and Technology, 6(4), 2347-2351 